\title{
Mycobacterium tuberculosis Nucleic Acid Measurement
}

National Cancer Institute

\section{Source}

National Cancer Institute. Mycobacterium tuberculosis Nucleic Acid Measurement. NCI Thesaurus. Code C92279.

The determination of the amount of Mycobacterium tuberculosis nucleic acid present in a sample. 